\title{
Extensional Seismogenic Stress and Tectonic Movement on the Central Region of the Tibetan Plateau
}

\author{
Jiren Xu and Zhixin Zhao \\ Institute of Geology, Chinese Academy of Geological Sciences, Beijing 100037, China \\ Correspondence should be addressed to Jiren Xu, xujiren1125@yahoo.com.cn \\ Received 6 February 2009; Revised 2 June 2009; Accepted 22 July 2009 \\ Recommended by Shuichi Kodaira
}

\begin{abstract}
Various earthquake fault types, mechanism solutions and stress fields, as well as GPS and geothermal data are analyzed for the study of the crustal movements on the Tibetan plateau and their tectonic implications. The results show that a lot of the normal faulting type-event concentrated at altitudes greater than $4000 \mathrm{~m}$ on the central Tibetan plateau. The altitudes concentrating normal faulting type-events can be zoned two parts: the western part, the Lhasa block, and the eastern part, the QiangtangChangdu region. The azimuths of T-axes are in a general E-W direction in the Lhasa block and NW-SE or NNW-SSE in the Qiangtang-Changdu region at the altitudes of the Tibetan plateau. The tensional stresses in E-W direction and NW-SE direction predominate normal faulting earthquake occurrence in the Lhasa block and the Qiangtang-Changdu region, respectively. The slipping displacements of the normal-faulting-type events have great components in near E-W direction and NW-SE direction in the Lhasa block and the Qiangtang-Changdu region, respectively. The extensions are probably an eastward or southeastward extensional motion, being mainly tectonic activity phenomena in the plateau altitudes. The extensional motions due to normalfault earthquakes are important tectonic activity regimes on the high altitudes of the plateau. The easterly crustal extensions on the plateau are attributable to the gravitational collapse of the high plateau and eastward extrusion of hotter mantle materials beneath the eastern boundary of the plateau. Numbers of thrust-fault and strike-slip-fault earthquakes with strong compressive stress in a general NNE-SSW direction occur on the edges of the plateau.
\end{abstract}

Copyright (C) 2009 J. Xu and Z. Zhao. This is an open access article distributed under the Creative Commons Attribution License, which permits unrestricted use, distribution, and reproduction in any medium, provided the original work is properly cited.

\section{Introduction}

The continental crust of the Indian plate collides with and subducts underneath Eurasia along great thrusts at the southern edge of the Himalayas. The compressive tectonic force due to the collision along the Himalayas between the Indian and Eurasian plates results in orogenic motions in the Himalayas, Tibetan plateau, and Altyn and Qilian mountains $[1,2]$. Such violent crustal movements and frequent and strong earthquakes extend to the Tianshan Mountains $[3,4]$. The compressive tectonic force affects crustal motions in the west of China and as far as Mongolia [5, 6]. Such motion and deformation make the Tibetan plateau and its surrounding areas one of the most active regions in terms of tectonics and seismicity in the world $[7,8]$. The synchronous temporal variations of the seismic activities on the Tibetan plateau region and its vicinity are related to the compressional collision between the Indian and Eurasian plates $[9,10]$.
Many papers have reported significant findings in the fields of tectonics and seismicity in this region [11, 12]. Besides the compressive tectonic motions, some extensional tectonic motions have been reported on the Tibetan plateau. The normal faulting type motions on the Tibetan plateau is attributable to the gravitational collapse of the high plateau [13]. Extensional crevices and grabens have been detected on the Tibetan plateau [14]. LANDSAT image data shows that extensional activity appears in the Tibetan region [15]. A Late Cenozoic E-W extension occurred on the Tibetan plateau [16]. The southern part of the plateau is cut by N-S trending normal faults that are the surface expression of regional stretching in an ESE direction, approximately parallel to the Himalayas [17].

In this analysis, the focal mechanisms for studying the tectonic characteristics in and around the plateau are analyzed. The extensional lithosphere motion on the Tibetan plateau and tectonic implications are investigated in detail, 


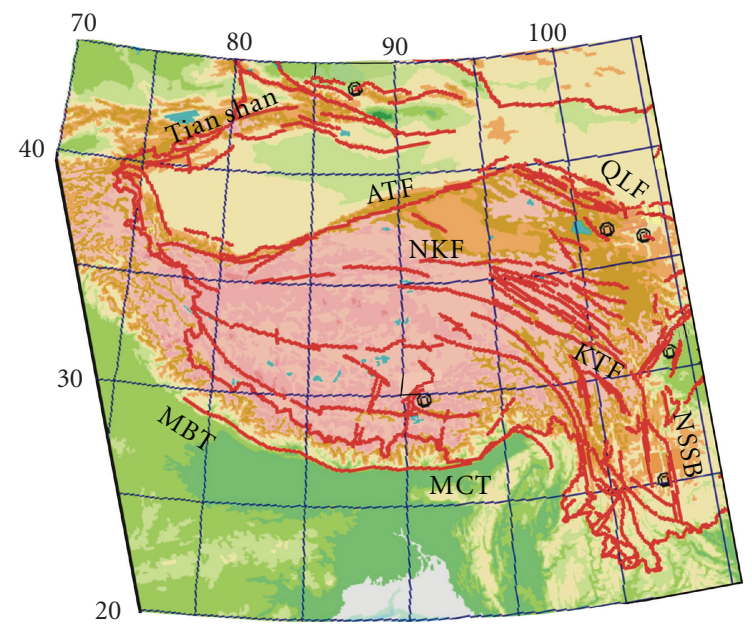

6000 0

$(\mathrm{m})$

Figure 1: Topographic and tectonic map of the Tibetan Plateau and surrounding regions. Solid lines show major faults (ATF: Altyn Tagh Fault; NKF: North Kunlun Fault; KTF: Kang Ding Fault; MCT: Main Central Thrust; MBT: Main Boundary Thrust; QLF: Qilian fault). NSSB: southern segment of the North-South Seismic belt.

based on the analyses of types of earthquake occurrences and the stress field, geothermal as well as GPS data.

Figure 1 shows the tectonic scheme of the Tibetan plateau and surrounding regions as a background map, including topographic information elevation and some faults. The elevation chart images the outline of the plateau.

\section{Data of Fault Plane Solutions}

Focal mechanism solutions of 924 earthquakes with magnitude equal to or greater than M4.5 on the Tibetan plateau and its vicinities during the period between 1933 and 2003 were analyzed and used in this study. In which, the selected events greater than or equal to $5.0(\mathrm{Mb})$ are more than 900. The depths of the events are less than $87 \mathrm{~km}$ in the lithosphere. The majority of events used in this analysis occurred mainly in the crust. The 217 fault plane solutions of events were determined form the distribution of the polarities of initial $\mathrm{P}$-wave motion on the focal hemisphere by the authors referring to data from the Bulletin of the International Seismological Center (ISC). Another 253 solutions determined by P-wave first motions are selected from the other authors referring to data from the Chinese Seismic Net and the Bulletin of the International Seismological Center (ISC) using P-wave first motions. (e.g., [4]). The above 470 solutions were determined using the first polarities of Pwaves of long- and short- period waveforms by the analog and digital records. The earthquake data from the Chinese Seismic Net have been collected from digital records since 2000.
All the solutions used in the analysis are well selected based on the contradictory rate of the plus to minus for the first polarity of P-wave motion. The focal mechanism solutions with symbolic contradictory ratio of $\mathrm{P}$-wave onsets less than 10 percent are of about 89 percent of the total solutions. Solutions with symbolic contradictory ratios between 11 and 15 percent are of 11 percent of the total solutions.

The others 454 CMT solutions (determined by the Centroid Moment tensor solutions) were selected from the Harvard University and USGS. CMT solutions for events with magnitude greater than 5.0 from 1977 to 2003 were also used in this study (e.g., $[18,19]$ ).

The characteristics of crust and lithosphere motions were analyzed based on the investigations of fault motions of events in and around the plateau. Earthquakes are divided into three types-normal, thrust, and strike-slip faulting events - depending on the plunge angles of the compressive stress $\mathrm{P}$ - and extensive stress T-axes. The statistical effect of characteristics of fault plane solutions were employed for analyses of the tectonics in and around plateau.

\section{Activity of Normal Faulting Earthquakes}

Earthquakes can generally be understood as brittle rock ruptures in the crust and lithosphere. So the study of faulting types of earthquakes may help us to understand the characteristics of lithosphere motion. The form of occurrence of earthquakes reflects the stress regime in a region. It is necessary to analyze fault types of earthquakes for investigation of tectonic motion characteristics on the Tibetan plateau and its surroundings. Figure 2(a) shows the fault plane solutions of events. Figure 2(b) visualizes the distributions of normal, thrust, and strike-slip faulting events that are divided according to the plunge angles of their compressive P- and extensional T-axes. It can be seen from Figure 2 that many events with normal faulting are clearly concentrated in the region with altitudes greater than about $4000 \mathrm{~m}$ on the Tibetan plateau. Normal faulting type regions $\mathrm{AB}$ and $\mathrm{CD}$ encircled by dashed line in Figure 2 are zoned based on the azimuths of T-axes.

In the surroundings of the normal faulting event region, the region in Tibet characterized by abundant normal faults is bounded on the north by the discontinuous zone of strikeslip and thrust faults in the Altyn and Qilian mountains. A number of large strike-slip faulting events occurred along the lines of the Karakorum and Altyn mountains. In the Qilian Mountains many thrust faulting events occurred besides the strike-slip faulting events. Seismic activity with normal faulting events disappears on the northern boundary of the plateau, where the style of seismic activity differs from that in the high-altitude region of the plateau. The thrust faulting events are clearly predominant in the Tianshan Mountains. The thrust faulting events occurred mainly along the western part of the Himalayan front to the Kashmir region. A number of strike-slip faulting events occurred along the eastern Himalayan front, except for some thrust faulting type events. The focal mechanism solutions show mainly strike-slip faulting events in the southern segment of the NSSB (North-South Seismic Belt), the eastern boundary 


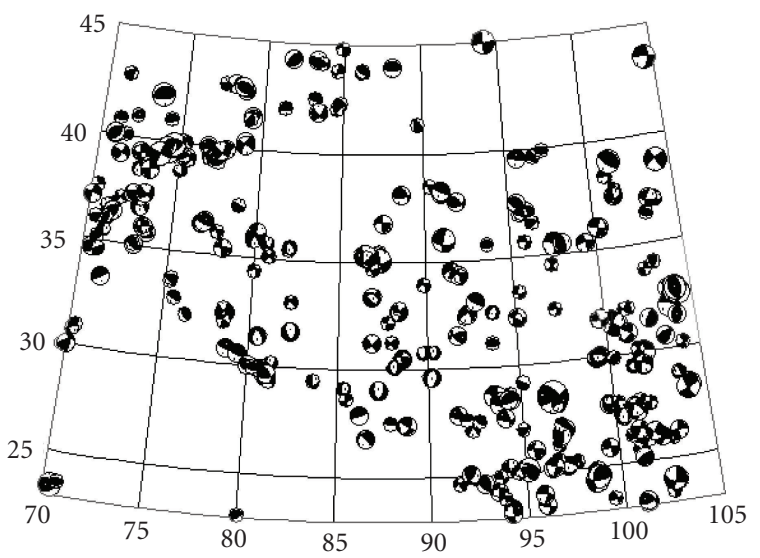

(a)

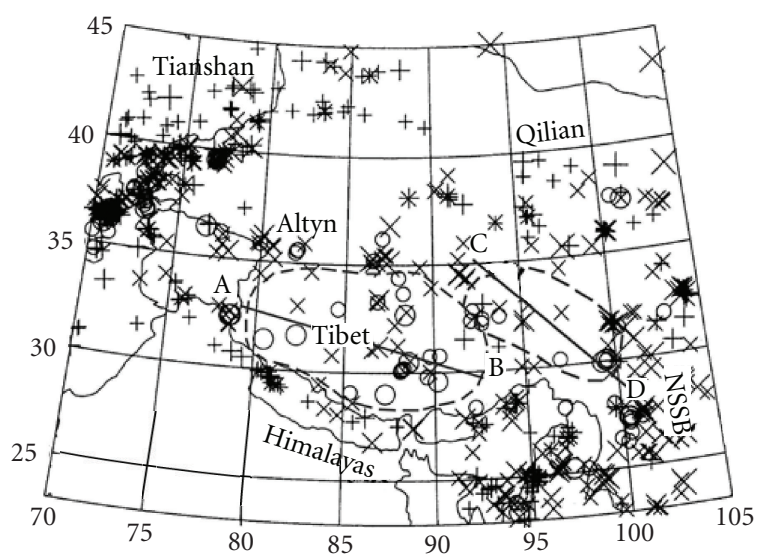

○ Normal fault

$\times$ Strike-slip fault

+ Reverse fault

FIgURe 2: (a) Fault plane solutions of events. (b) Distribution of normal, thrust, and strike-slip faulting events. The Tibetan plateau is surrounded by the Himalayas, Altyn, Qilian, and NSSB. Open circle: normal faulting event; Cross: strike-slip faulting event; Plus: reverse faulting event. Regions $\mathrm{AB}$ (the western part of the normal faulting event region, Lhasa block) and CD (the eastern part of the normal faulting event region, Qiangtang-Changdu region) enclosed with dashed lines.

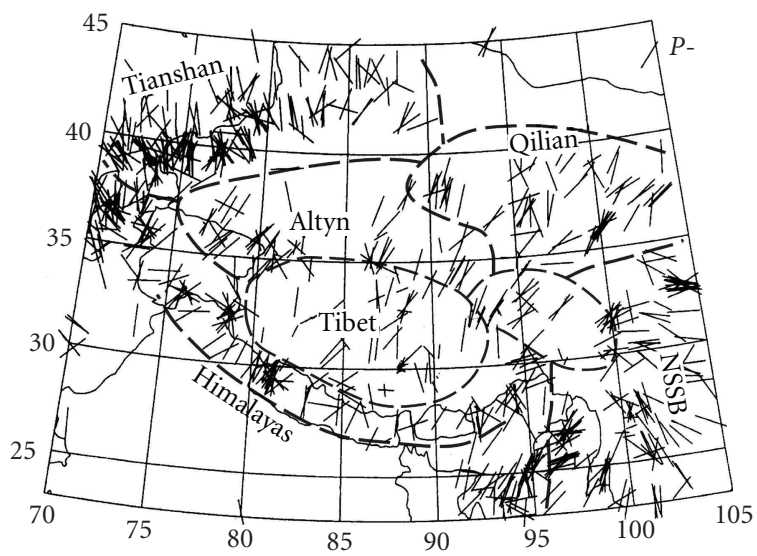

Figure 3: Distribution of compressive axes (P-) in and around the Tibetan plateau.

of the plateau. Many reverse and strike-slip faulting events occurred in the low surrounding regions of the Tibetan plateau. It may related with the strong compressive stress from the relative movement between the Indo-Australian and Eurasian plates acting on the surroundings of the plateau [20].

\section{Distributions of the Horizontal Components of the $\mathbf{P}$ - and T-Axes}

The stress field in and around the Tibetan plateau was investigated by analyzing the distributions of the $\mathrm{P}$ - and $\mathrm{T}$ axes of focal mechanism solutions for analyses of style of earthquake occurrence. Figures 3 and 4 show the horizontal

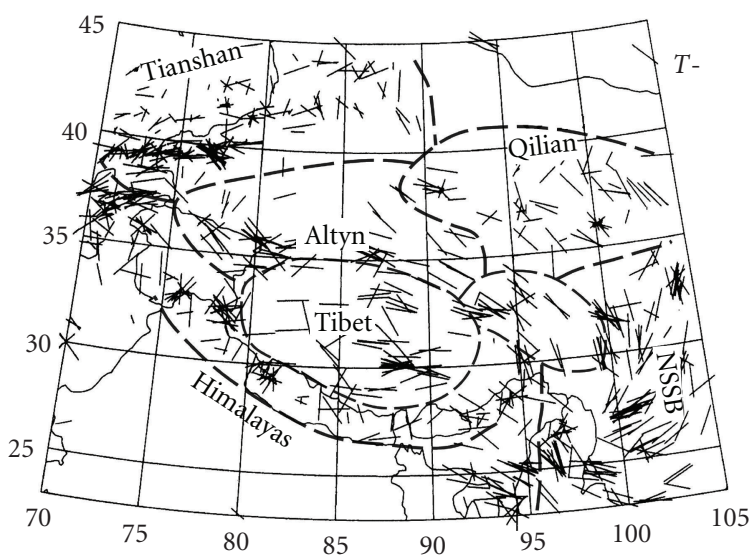

FIGURE 4: Distribution of extensional axes (T-) in and around the Tibetan plateau.

projections of the $\mathrm{P}$ - and $\mathrm{T}$-axes, respectively, in the last 70 years or so. It can be seen from the figures that the P-axes of events lie mainly in N-S to NE-SW directions on the plateau and its surrounding regions, with a few exceptional events. On the Himalayan fronts, the P-axes are almost in an NNE-SSW direction and are perpendicular to the Himalayan arc. The horizontal projections of some T-axes are very small there. The horizontal components of the Paxes are on average greater than those of the T-axes. This shows that the tectonic movements in the Himalayan front region are characterized by compressive stress in an NNESSW direction.

In the region north of the Himalayas and on the central Tibetan plateau (regions AB and CD enclosed with dashed 


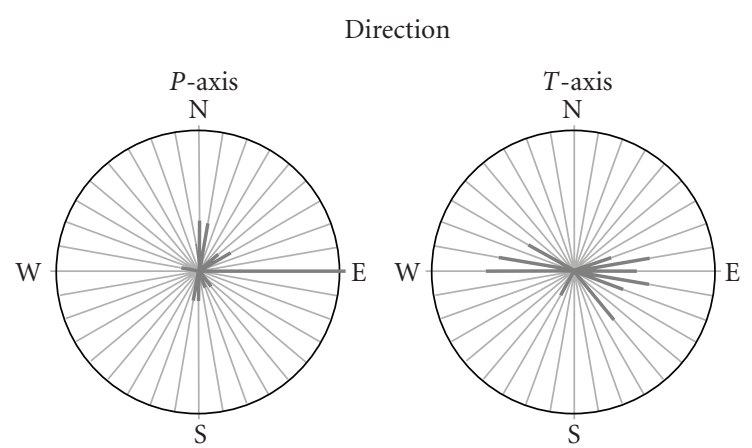

DIP
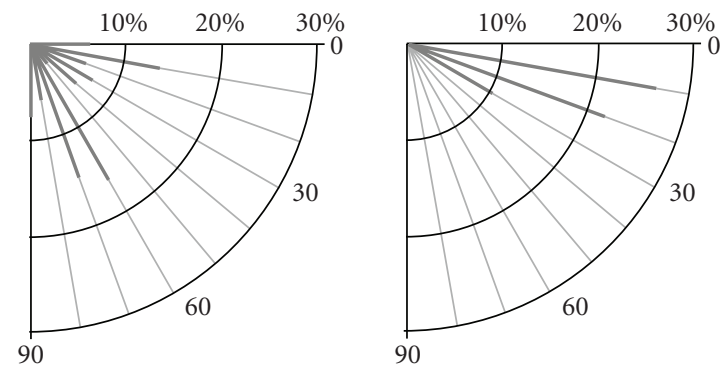

FIGURE 5: Statistical charts of azimuths and dips of compressive (P) and extensional $(\mathrm{T})$ axes in the southern and central part of the Tibetan plateau (AB region in Figure 2).

lines in Figure 2) the horizontal components of the P-axes as a whole become less than those of the T-axes, although the $\mathrm{P}$-axes basically do not change their orientations compared with those in the southern Himalayas. Most of T-axes lie nearly in an $\mathrm{E}-\mathrm{W}$ direction in the $\mathrm{AB}$ part. T-axes are nearly in an NW-SE or NNW-SSE direction in the CD part. The horizontal projections of the T-axes of some events are markedly large, especially in the regions of high elevation on the Tibetan plateau.

Figure 5 shows the statistical charts of azimuths and dips of the compressive $(\mathrm{P})$ and extensional $(\mathrm{T})$ axes in the Lhasa block ( $A B$ part in Figure 2). The extensive stress in the nearly $\mathrm{E}-\mathrm{W}$ direction dominates the seismic fault activities. The characteristics of the tectonic stress field in the regions of high elevation on the Tibetan plateau are clearly different from those in the southern margin of the Himalayan front.

The P-axes are mainly in an N-S to NE-SW direction on the northern borders of the Tibet plateau, Karakorum, Altyn, and Qilian Mountains. The orientations of the Taxes are in the general direction E-W to NNW-SSE. The horizontal projections of the $\mathrm{P}$ - and $\mathrm{T}$-axes are great and have almost same size as the whole of the Altyn Mountains. The horizontal components of some T-axes are somewhat small in the Qilian Mountains region, while those of the P-axes are great. Strong compressive stress has been identified in the region north of the Qilian Mountains. The horizontal projections of the $\mathrm{P}$-axes are large and lie in a general N-S direction in the Tianshan Mountains region. The horizontal components of the $\mathrm{T}$-axes are quite small there.

In the western part of the southern segment (south of $33^{\circ} \mathrm{N}$ ) of the NSSB (along about $96-104^{\circ} \mathrm{E}$ ) east of the

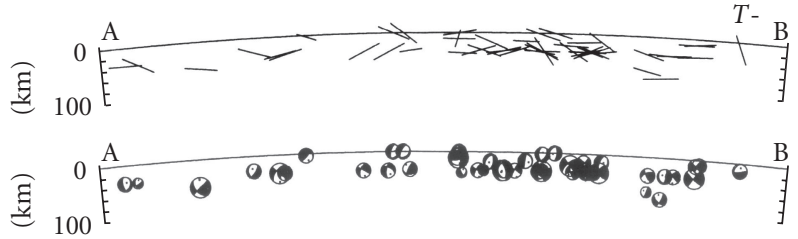

Figure 6: Projections of the vertical section along the line $A B$ in a general E-W direction for the T-axes and equal area projection diagrams of focal mechanism solutions of events (1933-2003, M $\geq$ $4.5)$ in the region encircled by a dashed line in Figure 2.

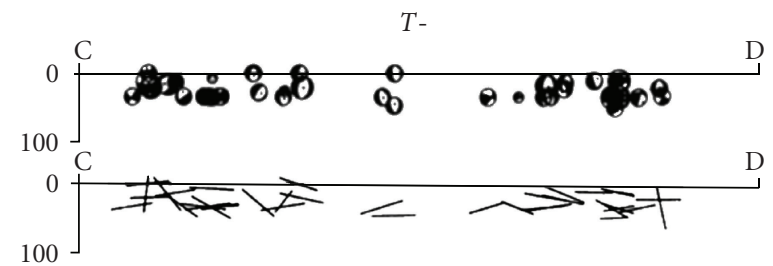

Figure 7: Projections of the vertical section along the line CD near the NW-SE direction for equal area projection diagrams and T-axes of focal mechanism solutions of events (1933-2003, $\mathrm{M} \geq 4.5)$ in the region encircled by the dashed line in Figure 2.

Tibetan plateau, the horizontal components of the P-axes lie almost in an NNE-SSW direction in the southern segment, changing to nearly NE-SW in the northern region of about latitude $33^{\circ} \mathrm{N}$. The P-axes lie in a general E-W direction in the regions around $33^{\circ} \mathrm{N}$ in the NSSB. The horizontal components of the T-axes lie in and around the NW-SE direction in the southern segment of the NSSB, which forms the eastern boundary of the Tibetan plateau. The horizontal components of the $\mathrm{P}$ - and $\mathrm{T}$-axes are almost the same in the eastern boundary.

\section{Projections for $\mathbf{P}$ - and T-Axes along Profiles}

Tectonic stress characteristics in the $\mathrm{AB}$ region of the central Tibetan plateau and its eastern vicinity, $\mathrm{CD}$ region, encircled with dashed lines as shown in Figure 2 are analyzed in detail for a further understanding of the tectonic implications of normal fault earthquakes on the plateau altitudes. Figures 6 and 7 show the projections for T-axes and stereonet diagrams of focal mechanism solutions on the vertical section beneath the lines $\mathrm{AB}$ and $\mathrm{CD}$ in the region in Figure 2. The maximum hypocentral depths of events are $78 \mathrm{~km}$ and $50 \mathrm{~km}$ in Figures 6 and 7, respectively. In the top profile of Figure 6, most of the T-axes lie in a nearly horizontal direction, with large components along the line $\mathrm{AB}$, in a general $\mathrm{E}-\mathrm{W}$ direction. These characteristics suggest that a horizontal extensional stress in a general E-W direction probably dominates the seismic fault motions in this region. Most of events occurring in this region are normal-faulting-type. The characteristics of normal-faulting events can also be identified in the bottom profile. This suggests that the horizontal motions of earthquake faults extend mainly in a general E-W direction. 


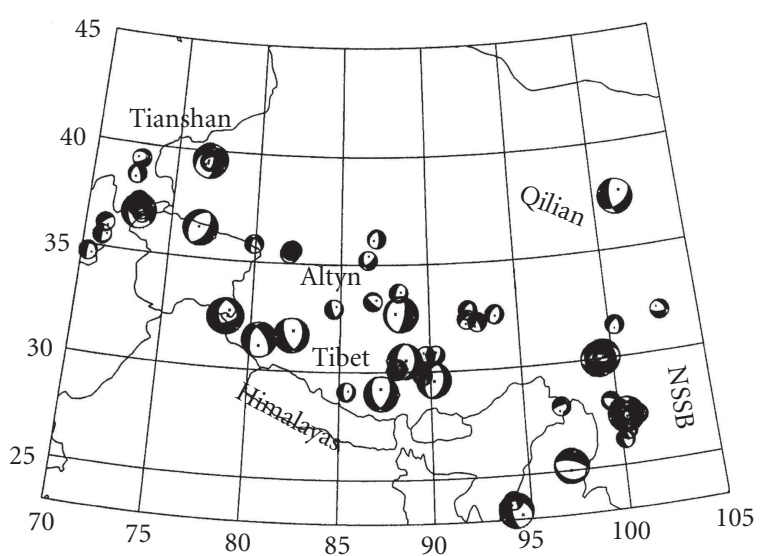

FIGURE 8: Distribution of the fault plane solutions for the normalfault-type events (1933-2003, $\mathrm{M} \geq 5$ ) in and around the Tibetan plateau.

With regard to the characteristics of the T-axes of focal mechanism solutions of events in profile CD in Figure 7, most of the T-axes lie in a generally horizontal direction, with large components, along the line CD in a nearly NW$\mathrm{SE}$ direction in Figure 7. These characteristics suggest that a horizontal extensional stress in the NW-NE direction probably dominates the seismic fault motions in the region $\mathrm{CD}$ in Figure 2. The characteristics of the stereonet diagrams of events can also be identified in the top profile.

\section{Normal-Faulting Earthquake Region}

The motional characteristics of normal-faulting-type events in Figure 2 are further analyzed by investigating the focal mechanism solutions. Figure 8 shows the stereonet diagrams of focal mechanism solutions only for normal faulting events with magnitudes greater than M5 in and around the Tibetan plateau. It can be seen that many normal-faulting-type events are concentrated on the Tibetan plateau. The strikes of many fault planes seem to be in a general N-S direction on high altitudes of the Tibetan plateau, corresponding to the region encircled by dashed line $A B$ in Figure 2. While the strike directions of the fault planes of normal faulting events occurring in the Tianshan Mountains and southern segment of the BSSN are scattered in different directions.

The characteristics of tectonic motions due to earthquakes can be further determined by analyzing in detail the strike directions of the fault planes of the events. Figure 9 shows the equal area projection diagrams of focal mechanism solutions of events in the $\mathrm{AB}$ region in Figure 2. The total number of events is 54 in the region enclosed by a dashed line in Figure 9. Few of them are thrust-fault-type events; some belong to the category of strike-slip-faulting events. The majority of them are normal-fault-type earthquakes, and 25 of them are almost perfect normal faulting events in which the strike directions of the two node planes lie in a general N-S direction. Their P-axes are almost located at centers of the equal area projection diagrams. This implies

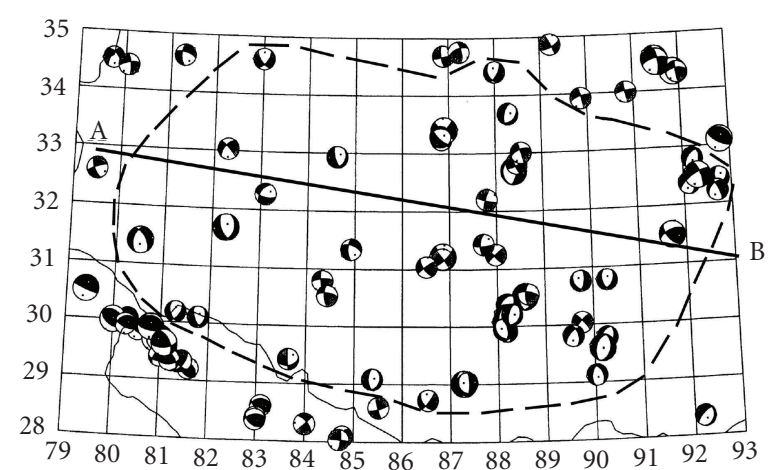

FIGURE 9: Distribution of the fault plane solutions of earthquakes in and around the $\mathrm{AB}$ region of the Tibetan plateau in Figure 2

that the P-axes are almost perpendicular to the surface, and the slip vectors of earthquake faults have major components in the E-W direction. Such events perhaps result in major horizontal extensions in the E-W direction whichever of the two node planes is taken as the source fault. Similarly, major horizontal extensions appeared in the NW-SE or NNW-SSE direction in the CD region in Figure 2.

Based on the above analyses, we can conclusively state that the crust extends in a general E-W direction in the $\mathrm{AB}$ region and NW-SE or NNW-SSE in the CD region at the altitudes of the Tibetan plateau due to the normal-faultingtype earthquakes.

\section{Crustal Movements from GPS and Geothermal Data}

The crustal east-west extensional motions are also confirmable by analyzing GPS and geothermal data. The rates of horizontal displacement lie in a general N-S direction on the western plateau and the western edge of the Kunlun Mountains. The eastward annually rates are between 15 and $20 \mathrm{~mm} / \mathrm{a}$ in the central plateau [8]. The annually rates of displacements lie identically in a generally easterly direction on the eastern boundary of the Tibetan plateau, in the southern segment of the NSSB, almost same as those in the central plateau. The eastward horizontal displacement components increase on average from the western plateau to the eastern margin of the plateau, in the northern segment of the NSSB, and through the central plateau. The rapid clockwise flow occurs around the syntaxis of the Himalayas on the eastern margin of the plateau [22]. The above analyses based on GPS findings at the surface imply that there exists an eastward crustal movement on the central and east plateau. This coincides with the extensional motion in the E-W and NW-SE directions due to the normal faulting events in the present analysis. Deformation of a continuous medium at depth best describes the present-day tectonics of the Tibetan plateau.

Geological tectonic and geothermal activities in the Lhasa block of the plateau are shown in Figure 10. Large mountains and early major compressive or compressive-shear faults 

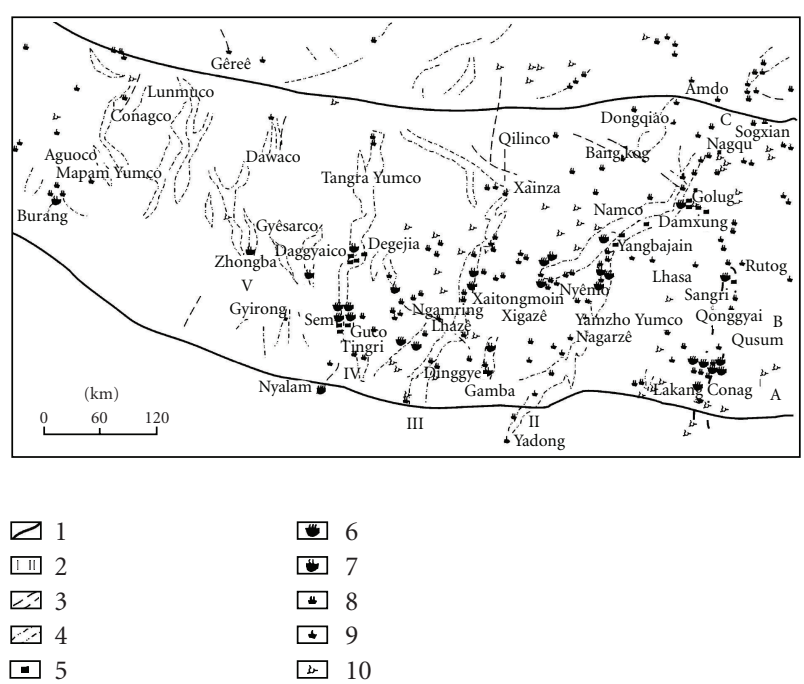

Figure 10: Distribution of hydrothermal manifestations in the Lhasa block of the Tibetan plateau (about $80-94^{\circ} \mathrm{E}, 27-33^{\circ} \mathrm{N}$ ). 1: Early major compressive or compressive-shear fault: the upper one is the Bangong-Nujiang suture zone, and the lower one is the Yarlung Zangbo Jiang suture zone; 2: the number of active tectonic zone; 3: boundary fault in active tectonic zone; 4 : faulted-depression zone in active tectonic zone; 5: site of sampling; 6: boiling spring; 7: hydrothermal explosion, geyser and boiling fountain; 8: thermal spring; 9: hot spring; 10: untested hydrothermal area (according to [21]).

mainly lie in an E-W direction in the plateau. The north boundary of the Lhasa block is the Bangong-Nujiang suture zone, and the southern boundary is the Yarlung Zangbo Jiang suture zone. A number of faulted-depression zones with nearly N-S or NNE strike direction, however, occur in the plateau. The faulted-depression zones with middle or small scales were probably formed by extensions in a generally east-west direction. Many extensional faulting activities along a general NEE direction exist on the northern part of the plateau also [23]. The Tibetan plateau is also a geothermally active zone. Many hot springs and geysers are located on the plateau. It is interested that many hydrothermal activities are gathered along the above extensional faulted depression zones. According to a discussion of the lithospheric thickness and hypocentral depth the faulteddepression zones with hydrothermal activities probably indicate that cracks occur in the depth due to extensional motion in the plateau also. The hypocenters of some normal faulting events mentioned in this paper extend also as deep as about $87 \mathrm{~km}$. The eastward extensional motions due to the normal faulting events probably extend to near the mantle.

Figure 11 shows the eastward extension regions on the central Tibetan plateau as the result. The extensional-motion regions marked by open rhombs and the direction of the eastward extension motions marked by open arrow on the plateau altitudes were substantiated based on the present analyses. The other tectonic properties are referenced the study of Avouac and Tapponnier [24].
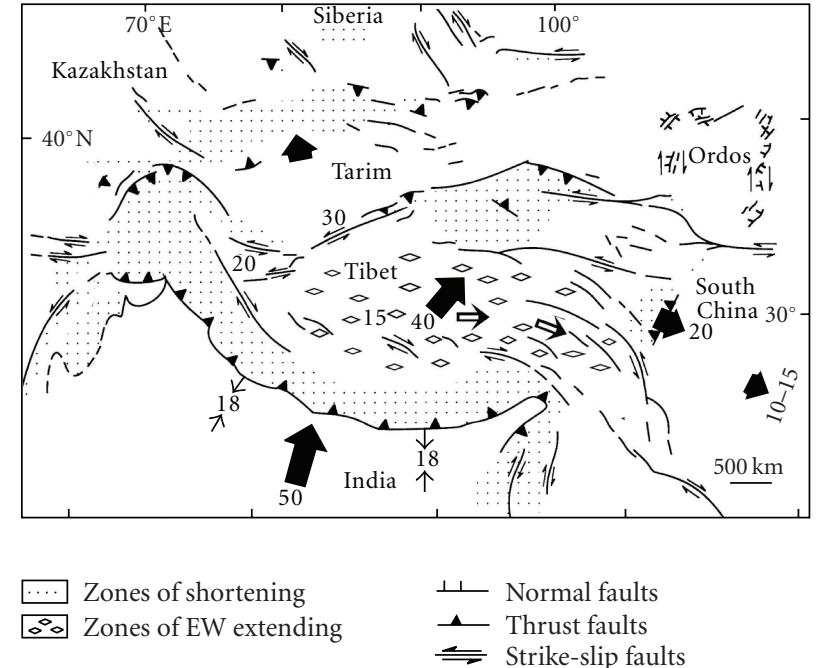

FIGURE 11: Eeastward extension regions on the central Tibetan plateau. Open rhomb area: extensional motion region obtained from the present analysis; open arrows: extensional direction of the plateau altitudes obtained in the present analysis (other tectonic properties are referenced the study of Avouac and Tapponnier [24]).

\section{Discussion}

The characteristics and mechanism of extensional motions at the high altitudes of the Tibetan plateau have been analyzed [25-29]. The activities of normal faulting earthquakes concentrated at high altitudes were investigated based on distribution characteristics of stress field, GPS data, as well as geothermal data in this paper. The extensionalstress-predominating earthquake activity at these altitudes superposes on the compressive stress predominating seismic activities on the edges of the plateau. The eastward extensional motion at high altitudes becomes an obviously important tectonic activity regime, although shortening deformation and movement in a nearly $\mathrm{N}-\mathrm{S}$ direction are revealed there too.

E-W extension shown by the normal faulting events behind the Himalayas may be related to tectonic stresses due to collision causing a wide distribution of P-axes in the general NNE-SSW or N-S directions in western China $[13,30]$. The strong compressive stress due to the northward movement of the Indian plate also causes the Tibetan plateau rise gradually [31]. The weight of a high plateau and the buoyancy acting on the bottom of the plateau crust from the mantle may create an additional vertical compressive stress which can result in the relaxation of the topography and corresponding thinning of the crust together with the normal faulting activity. The altitude of the Tibetan plateau is so high with respect to its surroundings that active normal faulting may also be caused by gravitational collapse toward the plateau margins $[25,32,33]$

A large number of thrust and strike-slip fault events occur in the front of the Himalayan Mountains. Many strikeslip fault events occur in the Karakorum and Altyn mountains. Thrust-faulting events occur frequently in regions of 
the Qilian and Tianshan mountains [34]. These findings show that strong compressive stresses exist on the southern, western, and northern boundaries of the plateau. Moreover, the GPS data show that the northward annual slip rates on the northern margin of the plateau, for example, in the Altyn and Qilian mountains, are one tenth of those on the Himalayan front [22, 35-37]. These findings imply that the northward motion of the Tibetan plateau shortened in the $\mathrm{N}-\mathrm{S}$ direction probably encounters strong obstructions at the western and northern margins [38].

A stress field in an NWW-SEE direction appears on the $\mathrm{CD}$ region in Figures 2 and 6. On the eastern margin of the Tibetan plateau, however, in the southern end of the NSSB, events are mainly of the strike-slip faulting type. The annually rates of crustal horizontal displacements are eastward and southward there. The extensional motion due to the relaxation of topography and/or gravitational collapse on the high plateau may easily become an eastward motion. The E-W stretching due to the normal fault events on the plateau is also consistent with eastward "escape-block" tectonics $[24,39]$.

Seismic velocity is rapid beneath the western Himalayas and western Tibet and is less rapid beneath north-central Tibet [40, 41]. The Tarim, Qaidam, Turfan, and Junggar basins on the western and northern sides of the plateau are underlain by large, rapid-velocity anomalies at depths of $100 \mathrm{~km}$ and $300 \mathrm{~km}$ [42]. The rapid-velocity anomalies are probably related to the ancient cold subduction materials beneath the Eurasian lithosphere of the Tethyan oceanic lithosphere [43]. It is a younger subduction history that dip angle of subduction is about $10 \pm 3^{\circ}$ [44]. The younger subduction motions encounter strong resistance from the front plate $[45,46]$. The seismic velocity beneath the NSSB is less than that beneath the central plateau [47]. The image implies that the mantle materials under the plateau thrust beneath the Yangtze block. This may imply that hotter materials lie beneath the eastern part of the plateau. So the hotter materials possibly modulate continuously northward convergence movements from the Indian plate in the Tibetan plateau by the eastward extrusion of mantle material. The latter may drag the lithosphere eastwards.

\section{Acknowledgments}

The authors are most grateful to the two reviewers for their helpful comments. This study was supported partly by the Nature Science Foundation of China (Grant no. 40674026) and Commonweal Special Science Foundation of China (Grant no. 200811037).

\section{References}

[1] P. Molnar and P. Tapponnier, "Cenozoic tectonics of Asia: effects of a continental collision," Science, vol. 189, no. 4201, pp. 419-426, 1975.

[2] P. Molnar, P. England, and J. Martinod, "Mantle dynamics, uplift of the Tibetan Plateau, and the Indian monsoon," Reviews of Geophysics, vol. 31, no. 4, pp. 357-396, 1993.
[3] C. Qin, C. Papazachos, and E. Papadimitriou, "Velocity field for crustal deformation in China derived from seismic moment tensor summation of earthquakes," Tectonophysics, vol. 359, no. 1-2, pp. 29-46, 2002.

[4] Z. Xu, "Modern tectonic stress in East Asia," Acta Seismologica Sinica, vol. 23, pp. 492-501, 2001.

[5] R. Van der Voo, W. Spakman, and H. Bijwaard, "Tethyan subducted slabs under India," Earth and Planetary Science Letters, vol. 171, no. 1, pp. 7-20, 1999.

[6] E. T. Brown, R. Bendick, D. L. Bourlès, et al., "Slip rates of the Karakorum fault, Ladakh, India, determined using cosmic ray exposure dating of debris flows and moraines," Journal of Geophysical Research B, vol. 107, no. 9, p. 2192, 2002.

[7] Y. Wang and $\mathrm{H}$. Xu, "Convergence rate of the India plate to Eurasia subduction beneath Qing-Zang plateau-inversion result from the GPS observed data," Chinese Journal of Geophysics, vol. 46, pp. 185-190, 2003.

[8] Q. Wang, P.-Z. Zhang, J. T. Freymueller, et al., "Presentday crustal deformation in China constrained by global positioning system measurements," Science, vol. 294, no. 5542, pp. 574-577, 2001.

[9] Z. Zhao, K. Oike, K. Matsumura, and Y. Ishikawa, "Stress field in the continental part of China derived from temporal variations of seismic activity," Tectonophysics, vol. 178, no. 24, pp. 357-372, 1990.

[10] Z. Zhao, J. Xu, and S. Horiuchi, "Differentiation operation in the wave equation for the pseudospectral method with a staggered mesh," Earth, Planets and Space, vol. 53, no. 5, pp. 327-332, 2001.

[11] Z. Zeng, Z. Ding, and Q. Wu, "Seismological evidence for the mulitiple incomplete crustal subductions in Himalaya and south Tibet," Chinese Journal of Geophysics, vol. 43, pp. 780797, 2000.

[12] Z. Fu, J. Xu, and J. Huang, "Numerical simulation of the compression uplift of the Qinghai-Xizang plateau," Chinese Journal of Geophysics, vol. 43, no. 3, pp. 346-355, 2000.

[13] J. Xu, Z. Zhao, Y. Ishikawa, and K. Oike, "Properties of the stress field in and around west China derived from earthquake mechanism solutions," in Bulletin of the Disaster Prevention Research Institute, vol. 38, pp. 49-78, Kyoto University, Kyoto, Japan, 1988.

[14] J. F. Deway and J. M. Bird, "Mountain belts and new global tectonics," Journal of Geophysical Research, vol. 75, no. 14, pp. 2625-2647, 1970.

[15] P. Molnar, "A review of the seismicity and the rates of active underthrusting and deformation at the Himalaya," Journal of Himalayan Geology, vol. 1, pp. 131-154, 1990.

[16] J. Ni and J. E. York, "Late Cenozoic tectonics of the Tibetan plateau," Journal of Geophysical Research, vol. 83, no. B11, pp. 5377-5384, 1978.

[17] R. Armijao, P. Tapponnier, J. L. Merccier, and T.-L. Han, "Quaternary extension in southern Tibet: field observations and tectonic implications," Journal of Geophysical Research, vol. 91, pp. 13083-13872, 1986.

[18] A. M. Dziewonski and J. H. Woodhouse, "An experiment in systematic study of global seismicity: centroid- moment tensor solutions for 201 moderate and large earthquakes in 1981," Journal of Geophysical Research, vol. 88, no. 4, pp. 3247-3271, 1983.

[19] A. M. Dziewonski, A. Friedman, D. Giardini, and J. H. woodhouse, "A experiment in systematic study of Geobal seismicity of 1982: centroid-moment tensor solution fot 308 earthquake," Physics of the Earth and Planetary Interiors, vol. 33, pp. 76-90, 1983. 
[20] C. Froidevaux and Y. Ricard, "Tectonic evolution of high plateaus," Tectonophysics, vol. 134, no. 1-3, pp. 227-238, 1987.

[21] H. Tonglin, "Relationship of the active structural system to geothermal activity in southern xizang (Tibet)," in Himalayan Geology, pp. 45-58, Geological Press, Beijing, China, 1981.

[22] P.-Z. Zhang, Z. Shen, M. Wang, et al., "Continuous deformation of the Tibetan Plateau from global positioning system data," Geology, vol. 32, no. 9, pp. 809-812, 2004.

[23] L. Yalin, W. Chengshan, Y. Haisheng, et al., "Characteristics of the shuanghu graben and cenozoic extension in northern Tibet," Science in China, Series D, vol. 44, supplement 1, pp. 285-291, 2001.

[24] J.-P. Avouac and P. Tapponnier, "Kinematic model of active deformation in central Asia," Geophysical Research Letters, vol. 20, no. 10, pp. 895-898, 1993.

[25] P. M. Blisniuk, B. R. Hacker, J. Glodny, et al., "Normal faulting in central Tibet since at least 13.5 Myr ago," Nature, vol. 412, no. 6847, pp. 628-632, 2001.

[26] H. Z. Wu, P. Ye, and D. Hu, Evolvement for Crustal Deformation and Tectonic Physiognomy, Geological Press, Beijing, China, 2003.

[27] J. F. Dewey, "Extensional collapse of orogens," Tectonics, vol. 7, no. 6, pp. 1123-1139, 1988.

[28] P. Molnar and P. Tapponier, "Active tectonics of Tibet," Journal of Geophysical Research, vol. 83, no. B11, pp. 5361-5375, 1978.

[29] S. L. Klemperer, "Crustal flow in Tibet: geophysical evidence for the physical state of Tibetan lithosphere, and inferred patterns of active flow," in Channel Flow, Ductile Extrusion and Exhumation in Continental Collision Zones, R. D. Law, M. P. Searle, and L. Godin, Eds., vol. 268, pp. 39-70, Geological Society, London, UK, 2006.

[30] J. Xu and K. Oike, "Stress characteristics in the southern segment of the North-South Seismic Belt," Acta Seismologica Sinica, vol. 17, pp. 31-40, 1995 (Chinese).

[31] R. S. Yeats and R. J. Lillie, "Contemporary tectonics of the Himalayan frontal fault system: folds, blind thrusts and the 1905 Kangra earthquake," Journal of Structural Geology, vol. 13, no. 2, pp. 215-225, 1991.

[32] S. Robert, K. S. Yeats, and R. A. Clarence, The Geology of Earthquakes, Oxford University Press, Oxford, UK, 1997.

[33] J. Lavé, J. P. Avouac, R. Lacassin, P. Tapponnier, and J. P. Montagner, "Seismic anisotropy beneath Tibet: evidence for eastward extrusion of the Tibetan lithosphere?" Earth and Planetary Science Letters, vol. 140, no. 1-4, pp. 83-96, 1996.

[34] T. M. Harrison, P. Copeland, W. S. F. Kidd, and A. Yin, "Raising tibet," Science, vol. 255, no. 5052, pp. 1663-1670, 1992.

[35] R. Bendick, R. Bilham, J. Freymueller, K. Larson, and G. Yin, "Geodetic evidence for a low slip rate in the Altyn Tagh fault system," Nature, vol. 404, no. 6773, pp. 69-72, 2000.

[36] R. Hetzel, S. Niedermann, M. Tao, et al., "Low slip rates and long-term preservation of geomorphic features in Central Asia," Nature, vol. 417, no. 6887, pp. 428-432, 2002.

[37] Z.-K. Shen, M. Wang, Y. Li, et al., "Crustal deformation along the Altyn Tagh fault system, western China, from GPS," Journal of Geophysical Research B, vol. 106, no. 12, pp. 3060730621, 2001.

[38] Z. Chen, B. C. Burchfiel, Y. Liu, et al., "Global positioning system measurements from eastern Tibet and their implications for India/Eurasia intercontinental deformation," Journal of Geophysical Research B, vol. 105, no. 7, pp. 16215-16227, 2000 .
[39] P. Tapponnier, "The Ailao Shan-Red River metamorphic belt: tertiary left-lateral shear between Indochina and South China," Nature, vol. 294, pp. 405-410, 1990.

[40] L. Bourjot and B. Romanowicz, "Crust and upper mantle tomography in Tibet using surface waves," Geophysical Research Letters, vol. 19, no. 9, pp. 881-884, 1992.

[41] R. Zhou, S. P. Grand, F. Tajima, and X.-Y. Ding, "High velocity zone beneath the southern Tibetan plateau from P-wave differential travel-time data," Geophysical Research Letters, vol. 23, no. 1, pp. 25-28, 1996.

[42] Y. Zhang and T. Tanimoto, "High-resolution global upper mantle structure and plate tectonics," Journal of Geophysical Research, vol. 98, pp. 9793-9823, 1993.

[43] P. Molnar, "The geologic evolution of the Tibetan plateau," American Scientist, vol. 77, no. 4, pp. 350-360, 1989.

[44] W. Zhao, K. D. Nelson, and Project INDEPTH Team, “Deep seismic reflection evidence for continental underthrusting beneath southern Tibet," Nature, vol. 366, no. 6455, pp. 557$559,1993$.

[45] J. Xu and K. Yoshiteru, "Geometry of slab, intraslab stress field and its tectonic implication in the Nankai trough, Japan," Earth, Planets and Space, vol. 54, no. 7, pp. 733-742, 2002.

[46] J. Xu, Z. Zhao, Y. Kono, and H. Kinoshita, "Regional characteristics of stress field and its dynamics in and around the Nankai Trough, Japan," Acta Geophysica Sinica, vol. 46, no. 4, pp. 488-494, 2003.

[47] Y. Zhang, "Three dimension upper mantle structure beneath East Asia and its tectonic implication," in Mantle Dynamics and Plate Interaction in East Asia, M. E. J. Flower, S.-L. Chung, C.-H. Lo, and T.-Y. Lee, Eds., pp. 11-23, American Geophysical Union, Washington, DC, USA, 2000. 

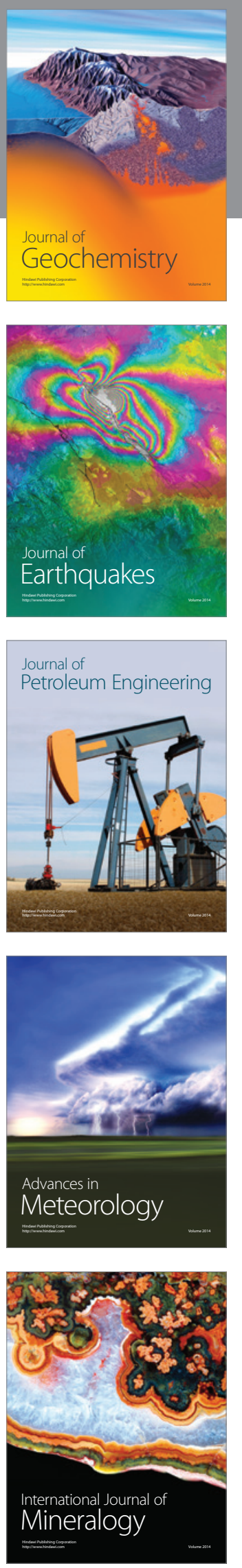
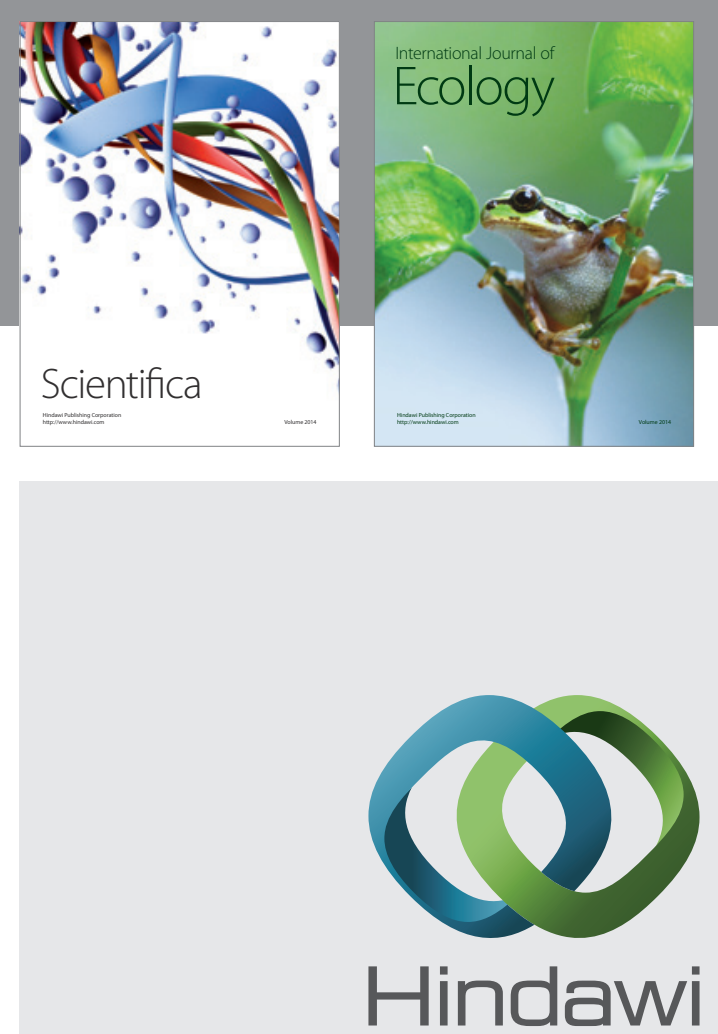

Submit your manuscripts at http://www.hindawi.com
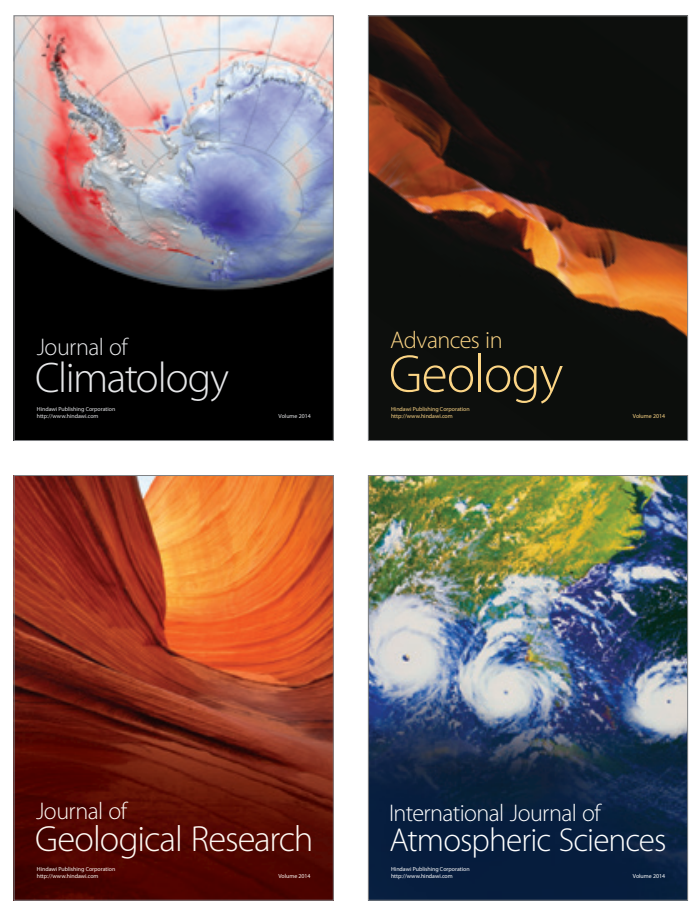
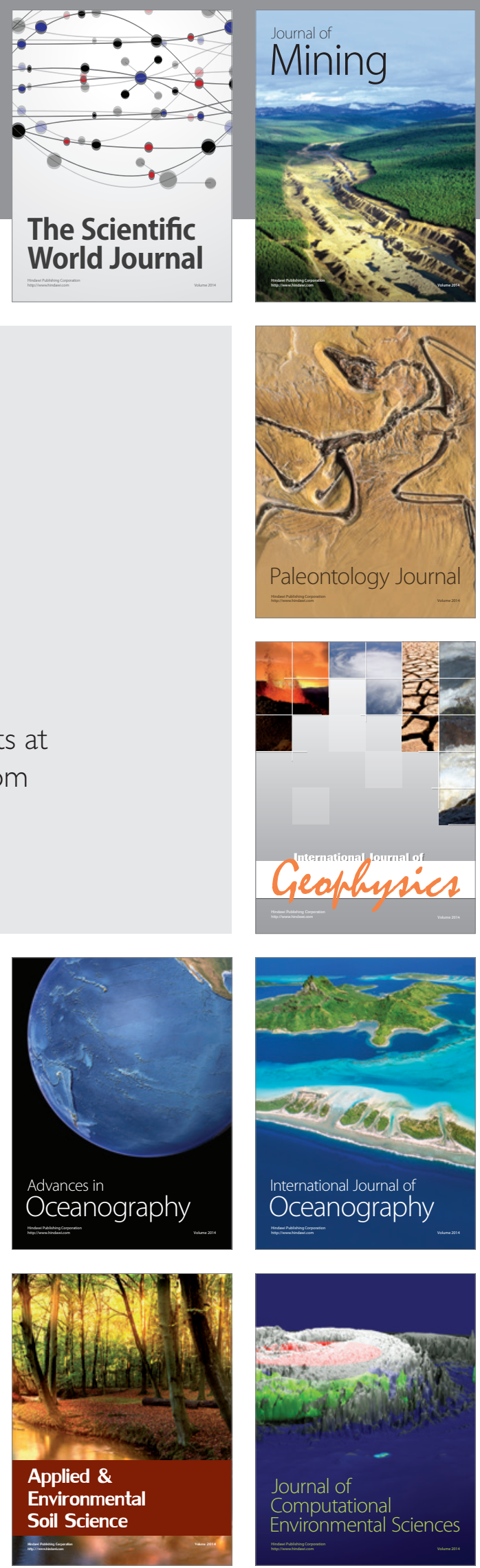